\title{
Vascular Fibrous Intimal Thickening Assessment
}

National Cancer Institute

\section{Source}

National Cancer Institute. Vascular Fibrous Intimal Thickening Assessment. NCI

Thesaurus. Code C135476.

An evaluation of the presence or degree of vascular fibrous intimal thickening present in a sample. 